\title{
Reinfection after treatment of first cerebrospinal fluid shunt infection: a prospective observational cohort study
}

\author{
Tamara D. Simon, MD, MSPH, ${ }^{1,3}$ Matthew P. Kronman, MD, MSCE, ${ }^{1,3}$ Kathryn B. Whitlock, MS, ${ }^{3}$ \\ Nancy E. Gove, PhD, ${ }^{3}$ Nicole Mayer-Hamblett, PhD, ${ }^{1,3}$ Samuel R. Browd, MD, PhD, ${ }^{2}$ \\ D. Douglas Cochrane, MD, ${ }^{4}$ Richard Holubkov, $\mathrm{PhD},{ }^{5}$ Abhaya V. Kulkarni, MD, PhD, ${ }^{4}$ \\ Marcie Langley, BS, ${ }^{6}$ David D. Limbrick Jr., MD, PhD, ${ }^{7}$ Thomas G. Luerssen, MD, ${ }^{8}$ \\ W. Jerry Oakes, MD, ${ }^{9}$ Jay Riva-Cambrin, MD, MSc, ${ }^{10}$ Curtis Rozzelle, MD, ${ }^{9}$ \\ Chevis Shannon, DrPH, ${ }^{11}$ Mandeep Tamber, MD, PhD, ${ }^{12}$ John C. Wellons III, MD, MSPH, ${ }^{11}$ \\ William E. Whitehead, MD, MPH, ${ }^{8}$ and John R. W. Kestle, MD, ${ }^{6}$ on behalf of the Hydrocephalus \\ Clinical Research Network
}

\begin{abstract}
Departments of 'Pediatrics and ${ }^{2}$ Neurosurgery, University of Washington/Seattle Children's Hospital; ${ }^{3}$ Seattle Children's Research Institute, Seattle, Washington; 4Division of Neurosurgery, The Hospital for Sick Children, University of Toronto, Ontario, Canada; ${ }^{5}$ Department of Pediatrics, University of Utah; ${ }^{6}$ Division of Pediatric Neurosurgery, Primary Children's Hospital, Department of Neurosurgery, University of Utah, Salt Lake City, Utah; ' ${ }^{D}$ epartment of Neurosurgery, St. Louis Children's Hospital, Washington University in St. Louis, Missouri; ${ }^{2}$ Division of Pediatric Neurosurgery, Texas Children's Hospital, Department of Neurosurgery, Baylor College of Medicine, Houston, Texas; ' 9 Section of Pediatric Neurosurgery, Children's of Alabama, Division of Neurosurgery, University of Alabama at Birmingham, Alabama; ${ }^{10}$ Department of Clinical Neurosciences, University of Calgary, Alberta, Canada; "11Department of Neurosurgery, Vanderbilt University, Nashville, Tennessee; and ${ }^{12}$ Division of Neurosurgery, Children's Hospital of Pittsburgh, Pennsylvania
\end{abstract}

OBJECTIVE CSF shunt infection requires both surgical and antibiotic treatment. Surgical treatment includes either total shunt removal with external ventricular drain (EVD) placement followed by new shunt insertion, or distal shunt externalization followed by new shunt insertion once the CSF is sterile. Antibiotic treatment includes the administration of intravenous antibiotics. The Hydrocephalus Clinical Research Network (HCRN) registry provides a unique opportunity to understand reinfection following treatment for CSF shunt infection. This study examines the association of surgical and antibiotic decisions in the treatment of first CSF shunt infection with reinfection.

METHODS A prospective cohort study of children undergoing treatment for first CSF infection at $7 \mathrm{HCRN}$ hospitals from April 2008 to December 2012 was performed. The HCRN consensus definition was used to define CSF shunt infection and reinfection. The key surgical predictor variable was surgical approach to treatment for CSF shunt infection, and the key antibiotic treatment predictor variable was intravenous antibiotic selection and duration. Cox proportional hazards models were constructed to address the time-varying nature of the characteristics associated with shunt surgeries.

RESULTS Of 233 children in the HCRN registry with an initial CSF shunt infection during the study period, 38 patients $(16 \%)$ developed reinfection over a median time of 44 days (interquartile range [IQR] 19-437). The majority of initial CSF shunt infections were treated with total shunt removal and EVD placement (175 patients; $75 \%$ ). The median time between infection surgeries was 15 days (IQR 10-22). For the subset of 172 infections diagnosed by CSF culture, the mean \pm SD duration of antibiotic treatment was $18.7 \pm 12.8$ days. In all Cox proportional hazards models, neither surgical approach to infection treatment nor overall intravenous antibiotic duration was independently associated with reinfection. The only treatment decision independently associated with decreased infection risk was the use of rifampin. While this finding did not achieve statistical significance, in all 5 Cox proportional hazards models both surgical approach (other than total shunt removal at initial CSF shunt infection) and nonventriculoperitoneal shunt location were consistently associated with a higher hazard of reinfection, while the use of ultrasound was consistently associated with a lower hazard of reinfection. CONCLUSIONS Neither surgical approach to treatment nor antibiotic duration was associated with reinfection risk.

ABBREVIATIONS $\mathrm{CCC}=$ complex chronic condition; $E V D=$ external ventricular drain; HCRN $=$ Hydrocephalus Clinical Research Network; IQR = interquartile range SUBMITTED March 7, 2017. ACCEPTED September 27, 2017.

INCLUDE WHEN CITING Published online February 2, 2018; DOI: 10.3171/2017.9.PEDS17112. 


\begin{abstract}
While these findings did not achieve statistical significance, surgical approach other than total removal at initial CSF shunt infection was consistently associated with a higher hazard of reinfection in this study and suggests the feasibility of controlling and standardizing the surgical approach (shunt removal with EVD placement). Considerably more variation and equipoise exists in the duration and selection of intravenous antibiotic treatment. Further consideration should be given to the use of rifampin in the treatment of CSF shunt infection. High-quality studies of the optimal duration of antibiotic treatment are critical to the creation of evidence-based guidelines for CSF shunt infection treatment.
\end{abstract}

https://thejns.org/doi/abs/10.3171/2017.9.PEDS17112

KEY WORDS cerebrospinal; shunt; infection; treatment; antibiotic; reinfection; hydrocephalus

$\mathrm{W}$ HILE lifesaving and the mainstay of hydrocephalus treatment, ${ }^{15} \mathrm{CSF}$ shunts can cause new and chronic surgical and medical problems in children with hydrocephalus. Mechanical malfunction is frequent, with $40 \%$ of shunts requiring surgical revision within 2 years. ${ }^{22}$ With each additional CSF shunt surgery, the risk of CSF shunt infection increases. ${ }^{2,25,49}$ CSF shunt infection rates range from $0 \%$ to $35 \%$ per surgery, $5,12,20,24,25$, $28,30,31,33,34,36,56$ with an average of 6\%-8\%.$^{18,19} \mathrm{CSF}$ shunt reinfection after an initial infection is frequent, and rates range from $12 \%$ to $26 \% .{ }^{17,21,49}$

Three detailed observational studies of treatment of CSF shunt infection with large numbers of children observed reinfection rates of $26 \%$ (18 of 70 patients), $20 \%$ (10 of 51 patients), and 26\% (31 of 118 patients), respectively. ${ }^{17,21,39}$ Investigators have noted considerable variation in surgical and antibiotic decisions for shunt infections that might explain reinfection..$^{25,28,37,52}$

Surgical decisions in the treatment of CSF shunt infection include either shunt removal with external ventricular drain (EVD) placement followed by new shunt insertion, or shunt externalization followed by shunt replacement once the CSF is sterile. While the benefit of each approach in preventing CSF shunt reinfection remains unclear, ${ }^{10,11}$, $14,21,26,43,48,54$ the growing consensus within the neurosurgical community has been to perform complete shunt removal at the time of the first infection surgery. ${ }^{17,52}$

Antibiotic decisions in the treatment of CSF shunt infection include the type and duration of empirical and targeted intravenous antibiotics. ${ }^{7,35,50}$ Here again, evidence is limited because no randomized controlled clinical trials have been conducted, and prior studies have been retrospective and limited in size. ${ }^{43}$ Duration of intravenous antibiotic use varies widely $y^{17,38}$ and depends, in part, on the surgical approach used, ${ }^{27,49}$ pathogen involved, ${ }^{7,46,55}$ CSF laboratory results, and persistence of the pathogen.

We sought a better understanding of the characteristics associated with reinfection following first CSF shunt infection because these may inform optimal treatment strategies at the time of first infection. The Hydrocephalus Clinical Research Network (HCRN) registry provides a unique opportunity to understand reinfection following treatment for CSF shunt infection. This study examines the association of surgical and antibiotic decisions in the treatment of first CSF shunt infection with reinfection.

\section{Methods}

\section{Setting}

The HCRN is a collaboration of 14 pediatric neurosurgical centers across North America. Of these, 7 were ac- tive during the study period and participated in this study: Children's of Alabama, Children's Hospital of Pittsburgh, The Hospital for Sick Children, Primary Children's Hospital, Seattle Children's Hospital, Texas Children's Hospital, and St. Louis Children's Hospital. HCRN registry data use was approved by HCRN and the institutional review boards at the University of Utah and Seattle Children's Hospital.

\section{Study Population and Data Collection}

Within the HCRN registry, data from each neurosurgical admission of each child are collected contemporaneously. Data collection started in April 2008 and, for this study, ended on December 31, 2012, except for children at The Hospital for Sick Children, who underwent follow-up until December 31, 2011. The final cohort included children whose first CSF shunt infection was recorded in the HCRN registry and whose initial CSF shunt placement and all subsequent shunt surgeries were also recorded in the HCRN registry during the study period $(n=151)$ and patients whose shunt surgery history (initial CSF shunt placement and subsequent CSF shunt revisions) was obtained retrospectively $(n=82)$.

The HCRN consensus definition was used for CSF shunt infection: ${ }^{19,38,42,45}$ 1) microbiological determination of bacteria present in a culture or Gram stain of CSF, wound swab, and/or pseudocyst fluid; 2) shunt erosion (visible hardware); or 3) abdominal pseudocyst (without positive culture); or 4) for children with ventriculoatrial shunts, presence of bacteria in a blood culture. The first CSF sample for diagnosis of infection was usually obtained from needle aspiration of the shunt reservoir under sterile conditions and before antibiotic initiation. To ensure that all infections were identified, all neurosurgical admissions involving 2 CSF shunt surgeries and $\geq 48$ hours of intravenous antibiotic treatment were reviewed by T.D.S. and local HCRN staff to clarify whether the infection criteria were met.

\section{Outcome Variable}

Reinfection was defined using the HCRN consensus definition of infection, as described above. The duration of follow-up for reinfection was through December 31, 2013, resulting in a minimum follow-up duration of 1 year. The at-risk period was defined as the period following first shunt infection in which a shunt was in place. Patients who died during treatment of first infection or who did not subsequently have a shunt in place were censored at day 1 and were excluded from the multivariable models used to predict reinfection. 


\section{Predictor Variables}

The key surgical predictor variable was the surgical approach to treatment for CSF shunt infection. ${ }^{37}$ Surgical approach was defined as 1) total shunt removal with EVD placement followed by new shunt insertion once the CSF was sterile, 2) distal shunt externalization followed by shunt replacement (externalization), 3) distal shunt externalization followed by EVD placement followed by new shunt insertion (failed externalization), or, rarely, 4) shunt revision, 5) shunt removal without replacement, or 6) no surgical treatment (i.e., shunt left in place).

The key antibiotic treatment predictor variable was intravenous antibiotic selection and duration, ${ }^{38}$ which was characterized following review by 2 authors (T.D.S. and M.P.K.) as follows: 1) concordant, defined by the start of intravenous antibiotic(s) to which the organism(s) grown in the CSF culture was sensitive; 2) concordant and appropriate, defined by the start of concordant intravenous antibiotic as previously described at a dose appropriate for weight and with adequate central nervous system penetration; or 3) broad spectrum, defined by the start of intravenous antibiotic(s) to treat gram-positive and gram-negative organisms. When not specifically provided, susceptibilities were anticipated when possible based on the organism (e.g., a methicillin-susceptible Staphylococcus aureus isolate was presumed to be susceptible to cefazolin even if not tested directly against it). Drug levels were not available for review in the determination of concordant and appropriate intravenous antibiotic use. Use of intrathecal antibiotics was handled as a dichotomous variable. Use of rifampin was considered synergistic and was not further incorporated into consideration of broad-spectrum or concordant antibiotics because susceptibility data were not available.

\section{Covariates}

Baseline characteristics included patient risk factors such as demographics, risk factors prior to initial CSF shunt placement, and treatment decisions at the time of CSF shunt placement and intervening revision surgeries as previously described and shown in Tables 1 and 2.38,41,42 Chronological age was handled as both a categorical and continuous variable. ${ }^{38,41,42}$ Complex chronic conditions (CCCs) were classified as previously described..$^{38,40}$ Of note, since June 2007 hospitals in HCRN have instituted an infection prevention bundle that is used at the time of the initial shunt placement and revision(s), although compliance with all aspects is variable..$^{18,19}$

Factors considered during the treatment of first CSF shunt infection (Table 3) included chronological age, complications after the first shunt infection, shunt location, ultrasound use, endoscope use, and antibiotic-impregnated catheter use. The duration of time between infection surgeries was determined to denote the time span between the first and final surgical approaches for infection treatment (e.g., shunt removal and EVD placement as the first surgery and shunt replacement as the second surgery). Next, we examined diagnostic and microbiological factors in CSF shunt infection (Table 4). ${ }^{45} \mathrm{We}$ considered the specific infection criteria that were met; organism(s) recovered in CSF, blood, and wound culture(s); presence of bacteremia (defined as any organism recovered in blood culture, except from children with ventriculoatrial shunts diagnosed by blood culture); and, where available within 48 hours of infection diagnosis, the results of the first CSF studies, including Gram staining, white and red blood cell counts, and glucose and protein levels.

Among the initial CSF shunt infections diagnosed by CSF culture, we examined additional diagnostic and microbiological factors, including time from first positive culture to first infection surgery, time from first persistently negative culture to final surgical approach for infection treatment, duration of positive CSF cultures, presence of intermittent negative CSF cultures (defined as 2 or more positive CSF cultures with the same organism and at least 1 intervening negative culture), and presence of secondary ventriculitis (recovery of a different organism than that initially recovered in the CSF culture). ${ }^{45}$

\section{Statistical Analyses}

The overall study population is described, as well as patients with and without reinfection, using the number and proportion for binary and categorical variables and mean and standard deviation or median (interquartile range [IQR]) for continuous variables. Patient characteristics, treatment decisions at initial CSF shunt placement, CSF shunt revision(s) before initial CSF shunt infection, initial CSF shunt infection (including diagnostic characteristics and surgical and antibiotic treatment decisions, such as antibiotic duration), and interval CSF shunt revision(s) were similarly described. In addition, the characteristics of each shunt revision surgery that occurred after the first CSF shunt infection and prior to CSF shunt reinfection or censoring-including shunt locations, use of ultrasonography and/or endoscopy, and use of antibiotic-impregnated catheter components - are described for patients with and without reinfection. Bivariate analyses of the surgical decisions by the center were conducted to assess systematic differences in surgical and antibiotic treatment decisions.

Associations of clinical characteristics and treatment decisions at the time of the first CSF shunt infection with reinfection risk were individually examined in separate Cox proportional hazards models. For these models, because endoscope and ultrasound use tend to be mutually exclusive, we created a visualization use variable at each surgical time point that included only endoscope use, only ultrasound use, use of both, and use of neither. We also trichotomized antibiotic duration at CSF shunt infection as short (< 7 days), intermediate (8-14 days), and long ( $>14$ days). Time-varying characteristics associated with shunt revisions following first CSF shunt infection were analyzed using the extension of the Cox proportional hazards to the count processes proposed by Andersen and Gill. ${ }^{3,44}$ Factors selected a priori, as well as statistically significant predictors $(\alpha=0.10)$ that were not collinear, were entered into a multivariable Cox proportional hazards model (full model). To ease interpretation, a second version of the full model that includes only children who did not undergo any revisions before reinfection $(n=147)$ is also provided. Factors selected a priori included age, etiology of hydrocephalus, surgical approach to infection treatment, and overall intravenous antibiotic use. Statistically significant predictors $(\alpha=0.10)$ that were not collinear include CCCs, 
TABLE 1. Characteristics of children with and without CSF shunt reinfection at the time of initial CSF shunt placement

\begin{tabular}{|c|c|c|c|}
\hline Characteristic & No Reinfection & Reinfection & Entire Cohort \\
\hline No. of patients & 195 & 38 & 233 \\
\hline Median chronological age (IQR), wks & $13(2-54)$ & $20(9-33)$ & $14(2-48)$ \\
\hline Median gestational age (IQR), wks ${ }^{*} \dagger$ & $37(26-39)$ & $30(25-38)$ & $36(26-39)$ \\
\hline \multicolumn{4}{|l|}{ Sex } \\
\hline Male & $105(54)$ & $18(47)$ & $123(53)$ \\
\hline Female & $90(46)$ & $20(53)$ & $110(47)$ \\
\hline \multicolumn{4}{|l|}{ Ethnicity } \\
\hline Non-Hispanic white & $106(54)$ & $18(47)$ & $124(53)$ \\
\hline African American & $31(16)$ & $8(21)$ & $39(17)$ \\
\hline Hispanic & $27(14)$ & $5(13)$ & $32(14)$ \\
\hline Other* & $31(16)$ & $7(18)$ & $38(16)$ \\
\hline \multicolumn{4}{|l|}{ Insurance } \\
\hline Public & $86(44)$ & $18(47)$ & $104(45)$ \\
\hline Private & $77(40)$ & $16(42)$ & $93(40)$ \\
\hline Self-pay & $7(4)$ & $3(8)$ & $10(4)$ \\
\hline Other & $4(2)$ & $0(0)$ & $4(2)$ \\
\hline Government (Canada only) & $21(11)$ & $1(3)$ & $22(9)$ \\
\hline Mean birth weight (SD), kgfף & $2.5(1.2)$ & $1.8(1.3)$ & $2.3(1.3)$ \\
\hline Median weight at op (IQR), $\mathrm{kg} \S$ & $4.1(2.8-11.2)$ & $4.2(3.0-8.6)$ & $4.1(2.9-10.3)$ \\
\hline \multicolumn{4}{|l|}{ Etiology of hydrocephalus } \\
\hline Post-intraventricular hemorrhage due to prematurity* & $58(30)$ & $18(47)$ & $76(33)$ \\
\hline $\begin{array}{l}\text { Congenital (communicating congenital, other congenital, } \\
\text { encephalocele, craniosynostosis) }\end{array}$ & $37(19)$ & $6(16)$ & $43(18)$ \\
\hline Myelomeningocele & $35(18)$ & $4(11)$ & $39(17)$ \\
\hline Tumor (supratentorial, posterior fossa, midbrain) & $24(12)$ & $2(5)$ & $26(11)$ \\
\hline Cyst (posterior fossa, intracranial)ף & $9(4)$ & $5(13)$ & $14(6)$ \\
\hline Aqueductal stenosis & $10(5)$ & $2(5)$ & $12(5)$ \\
\hline After head injury & $6(3)$ & $1(3)$ & $7(3)$ \\
\hline Postinfectious & $7(4)$ & $0(0)$ & $7(3)$ \\
\hline Other & $7(4)$ & $0(0)$ & $7(3)$ \\
\hline Spontaneous hemorrhage & $2(1)$ & $0(0)$ & $2(1)$ \\
\hline \multicolumn{4}{|l|}{ CCCs } \\
\hline 0 (except hydrocephalus) & $113(58)$ & $14(37)$ & $127(55)$ \\
\hline $1^{*}$ & $67(34)$ & $17(45)$ & $84(36)$ \\
\hline$\geq 2 \pi$ & $15(8)$ & $7(18)$ & $22(9)$ \\
\hline Gastrostomy** & $19(17)$ & $3(13)$ & $22(16)$ \\
\hline Tracheostomy** & $3(3)$ & $2(9)$ & $5(4)$ \\
\hline \multicolumn{4}{|c|}{$\begin{array}{l}\text { Values are shown as the number of patients }(\%) \text { unless indicated otherwise. } \\
\text { * Significant difference between groups }(p<0.10) \text { according to the unadjusted Cox proportional hazards models. } \\
\text { † Reported for } 210 \text { children. } \\
\text { † Reported for } 160 \text { children. } \\
\text { § Reported for the prospective cohort of } 151 \text { children. } \\
\text { † Significant difference between groups }(p<0.05) \text { according to the unadjusted Cox proportional hazards models. } \\
\text { ** Performed for } 137 \text { children. }\end{array}$} \\
\hline
\end{tabular}

revisions before initial CSF shunt infection, visualization before initial CSF shunt infection, rifampin use, and, for children with revisions after initial CSF shunt infection, visualization at last surgery before reinfection/censor, revision(s) before reinfection/censoring, and last shunt location. Factors that were not included in models due to collinearity included gestational age and birth weight (col- linear with etiology of post-intraventricular hemorrhage due to prematurity), shunt locations at all surgical time points before reinfection (collinear with last shunt location), visualization at initial CSF shunt placement (collinear with visualization before initial CSF shunt infection and at last surgery before reinfection/censor), and broadspectrum intravenous antibiotic use (collinear with overall 
TABLE 2. Treatment decisions at the time of initial CSF shunt placement and shunt revision before initial CSF shunt infection in children with and without CSF shunt reinfection

\begin{tabular}{|c|c|c|c|}
\hline Variable & $\begin{array}{c}\text { No } \\
\text { Reinfection }\end{array}$ & Reinfection & $\begin{array}{l}\text { Entire } \\
\text { Cohort }\end{array}$ \\
\hline No. of patients & 126 & 25 & 151 \\
\hline \multicolumn{4}{|l|}{ Initial CSF shunt placement } \\
\hline \multicolumn{4}{|l|}{ Shunt location (proximal-distal) } \\
\hline Ventriculoperitoneal & $122(97)$ & $20(80)$ & $142(94)$ \\
\hline Cystoperitoneal & $3(2)$ & $1(4)$ & $4(2)$ \\
\hline Subdural-peritoneal ${ }^{*}$ & $0(0)$ & $2(8)$ & $2(1)$ \\
\hline Complex peritoneal* $^{*}$ & $0(0)$ & $1(4)$ & $1(1)$ \\
\hline Ventriculoatrial & $1(1)$ & $0(0)$ & $1(1)$ \\
\hline Subdural-atrial* & $0(0)$ & $1(4)$ & $1(1)$ \\
\hline Ultrasound use & $48(38)$ & $0(0)$ & $48(32)$ \\
\hline Endoscope use $^{*}$ & $34(27)$ & $13(52)$ & $47(31)$ \\
\hline $\begin{array}{l}\text { Antibiotic-impregnated cath- } \\
\text { eter use }\end{array}$ & $30(24)$ & $1(4)$ & $31(21)$ \\
\hline \multicolumn{4}{|l|}{ CSF shunt revisions } \\
\hline \multicolumn{4}{|l|}{ No. before initial infection $†$} \\
\hline 0 & $111(57)$ & $13(34)$ & $124(53)$ \\
\hline $1^{*}$ & $34(17)$ & $12(32)$ & $46(20)$ \\
\hline$\geq 2$ & $50(26)$ & $13(34)$ & $63(27)$ \\
\hline \multicolumn{4}{|l|}{ Shunt location (proximal-distal) } \\
\hline Ventriculoperitoneal & $118(93)$ & $18(72)$ & $136(90)$ \\
\hline Cystoperitoneal & $4(3)$ & $1(4)$ & $5(3)$ \\
\hline Subdural-peritoneal & $0(0)$ & $1(4)$ & $1(1)$ \\
\hline Complex peritoneal* & $2(2)$ & $3(12)$ & $5(3)$ \\
\hline Ventriculoatrial & $2(2)$ & $1(4)$ & $3(2)$ \\
\hline Subdural-atrial ${ }^{*}$ & $0(0)$ & $1(4)$ & $1(1)$ \\
\hline Ultrasound use* & $45(36)$ & $2(8)$ & $47(31)$ \\
\hline Endoscope use & $29(23)$ & $13(52)$ & $42(28)$ \\
\hline $\begin{array}{l}\text { Antibiotic-impregnated cath- } \\
\text { eter use }\end{array}$ & $34(27)$ & $4(16)$ & $38(25)$ \\
\hline
\end{tabular}

Values are shown as the number of patients (\%).

* Significant difference between groups $(p<0.05)$ according to unadjusted

Cox proportional hazards models.

† For entire cohort of 233 children.

$\ddagger$ Significant difference between groups $(p<0.10)$ according to unadjusted Cox proportional hazards models.

intravenous antibiotic use). The risks of reinfection associated with each characteristic are reported as hazard ratios and associated $95 \%$ confidence intervals.

In addition, 3 alternative model definitions were examined. First, the proportional hazards assumption was challenged by adding the interactions of the time-varying covariates with time since the last procedure. Selection of nonproportional hazards adjustment (time-varying hazards model) was based on the model's stability, Akaike's information criterion, and Bayesian information criterion. Second, automated stepwise model selection was used to reduce the number of terms in the multivariable Cox proportional hazards model (reduced model). Selection criteria for entry and exit were both $\alpha=0.10$. Finally, to examine the robustness of the model in a relatively lowrisk and homogenous cohort, the time-varying hazards model was applied to the subset of patients with all known shunts placed in the peritoneal location (ventriculoperitoneal shunt model).

All statistical analyses were performed using SAS (version 9.2; SAS Institute).

\section{Results \\ Study Cohort at Time of CSF Shunt Infection}

Of 3131 children in the HCRN registry during the study period, $233(7.4 \%)$ met the inclusion criteria with an initial CSF shunt infection. Of these 233 children, 38 patients $(16 \%)$ developed reinfection. Baseline patient and treatment factors, including those of patients with and without reinfection, are shown in Tables 1 and 2. Most children underwent initial CSF shunt placement when they were younger than 6 months (156 patients; 67\%), at a median age of 14 weeks (IQR 2-48 weeks). The etiology of hydrocephalus was distributed among post-intraventricular hemorrhage due to prematurity (76 patients; $33 \%$ ), congenital (43 patients; 18\%), myelomeningocele (39 patients; 17\%), tumor (26 patients; 11\%), and other etiologies. Significant numbers of children had additional neuromuscular (53 patients; 23\%), cardiac (26 patients; $11 \%$ ), respiratory (25 patients; $11 \%$ ), and congenital/genetic (22 patients; 9\%) CCCs. Cardiac and congenital/genetic $\mathrm{CCCs}$ were associated with reinfection (data not shown). The majority of children had 0 CSF shunt revisions (124 patients; 53\%) prior to CSF shunt infection. The median time to first infection from previous CSF shunt surgery was 33 days (IQR 15-77 days) (data not shown). At the time of initial CSF shunt infection, the cohort had a median age of 78 weeks (IQR 18-360 weeks). The median duration of follow-up for the entire cohort was 742 days (IQR 406-1260 days), and the median time to reinfection was 44 days (IQR 19-437 days).

The overall diagnostic characteristics of the entire cohort of patients with initial CSF shunt infection and patients with and without reinfection are provided in Table 4. The majority of patients were diagnosed by CSF culture (172 patients; 74\%). The most common initial organisms recovered included coagulase-negative staphylococcus (55 patients; $32 \%$ ), S. aureus (49 patients; $28 \%$ ), and gramnegative bacilli (38 patients; $22 \%$ ).

\section{Surgical Treatment for First CSF Shunt Infection}

The majority of initial CSF shunt infections were treated with total shunt removal and EVD placement (175 patients; 75\%). The median time between infection surgeries was 15 days (IQR 10-22 days). As shown in Table 3, the median time from first negative CSF culture to final surgical approach to treat infection was 13 days (IQR 9-20 days).

\section{Antibiotic Treatment for First CSF Shunt Infection}

For the subset of 172 infections diagnosed by CSF culture, the mean \pm SD duration of concordant intravenous antibiotic treatment was 18.7 days (SD 12.8 days) (Table 3 ). The mean duration of concordant and appropriate in- 
TABLE 3. Treatment decisions at the time of initial CSF shunt infection and intervening shunt revisions in children with and without CSF shunt reinfection

\begin{tabular}{|c|c|c|c|}
\hline Variable & No Reinfection & Reinfection & Entire Cohort \\
\hline No. of patients & 195 & 38 & 233 \\
\hline \multicolumn{4}{|l|}{ Initial CSF shunt infection } \\
\hline Median chronological age at infection (IQR), wks & 72 (16 to 377$)$ & 80 (29 to 292$)$ & 78 (18 to 360$)$ \\
\hline Concordant IV antibiotic use ${ }^{*}$ & $144(98)$ & $24(96)$ & $168(98)$ \\
\hline Mean duration $\pm \mathrm{SD}$, days & $18.8 \pm 13.0$ & $18.3 \pm 11.9$ & $18.7 \pm 12.8$ \\
\hline Concordant \& appropriate IV antibiotic use ${ }^{*}$ & $133(91)$ & $22(88)$ & $155(90)$ \\
\hline Mean duration $\pm \mathrm{SD}$, days & $15.5 \pm 12.4$ & $17.5 \pm 12.1$ & $15.8 \pm 12.4$ \\
\hline Broad-spectrum IV antibiotic use $†$ & $164(84)$ & $30(79)$ & $194(83)$ \\
\hline Median duration (IQR) & $5.2(2.8$ to 12.6$)$ & $11.2(3.0$ to 17.5$)$ & $5.3(2.8$ to 13.6$)$ \\
\hline Use of intrathecal antibiotics & $130(67)$ & $23(61)$ & $153(66)$ \\
\hline Use of rifampin† & $34(17)$ & $2(5)$ & $36(15)$ \\
\hline \multicolumn{4}{|l|}{ Surgical approach to treatment } \\
\hline Total shunt removal \& EVD placement & $149(77)$ & $26(68)$ & $175(75)$ \\
\hline Externalization & $14(7)$ & $4(11)$ & $18(8)$ \\
\hline Failed externalization & $8(4)$ & $5(13)$ & $13(6)$ \\
\hline$\geq 1$ components revised & $6(3)$ & $2(5)$ & $8(3)$ \\
\hline Shunt removed after infection treatment & $12(6)$ & Not at risk & $12(5)$ \\
\hline Shunt left in place & $4(2)$ & $1(3)$ & $5(2)$ \\
\hline Died during treatment & $2(1)$ & Not at risk & $2(1)$ \\
\hline Median time from 1st positive CSF culture to 1st infection op (IQR), days & $0.3(-0.1$ to 0.8$)$ & $0.3(-0.2$ to 0.8$)$ & $0.3(-0.1$ to 0.8$)$ \\
\hline Median time btwn infection surgeries (IQR), days ${ }^{* *}$ & $14(10$ to 21$)$ & $17(10$ to 27$)$ & $15(10$ to 22$)$ \\
\hline Median time from 1st negative CSF culture to final infection op (IQR), days* ${ }^{*} \dagger \dagger$ & $13(9$ to 18$)$ & $16(9$ to 22$)$ & 13 (9 to 20$)$ \\
\hline \multicolumn{4}{|l|}{ Complicationsł } \\
\hline Medical & $16(16)$ & $4(24)$ & $20(17)$ \\
\hline Neurological/surgical & $24(23)$ & $6(35)$ & $30(25)$ \\
\hline \multicolumn{4}{|l|}{ 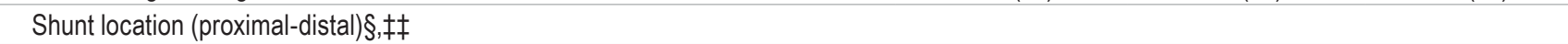 } \\
\hline Ventriculoperitoneal & $157(87)$ & $24(63)$ & $181(83)$ \\
\hline Ventriculoatrial§ & $8(4)$ & $6(16)$ & $14(6)$ \\
\hline Complex peritoneal† & $4(2)$ & $3(8)$ & $7(3)$ \\
\hline Cystoperitoneal & $5(3)$ & $1(3)$ & $6(3)$ \\
\hline Ventriculopleural† & $3(2)$ & $2(5)$ & $5(2)$ \\
\hline Subdural-peritoneal & $2(1)$ & $1(3)$ & $3(1)$ \\
\hline Complex atrial & $1(0)$ & $1(3)$ & $2(1)$ \\
\hline Lumboperitoneal & $1(0)$ & $0(0)$ & $1(0)$ \\
\hline Ultrasound use,$\S \S$ & $59(33)$ & $5(14)$ & $64(30)$ \\
\hline Endoscope use§,§§ & $52(29)$ & $21(57)$ & $73(34)$ \\
\hline Antibiotic-impregnated catheter use§§ & $56(32)$ & $8(22)$ & $64(30)$ \\
\hline \multicolumn{4}{|l|}{ Interval CSF shunt revision } \\
\hline \multicolumn{4}{|l|}{ Revisions after initial infection \& before reinfection } \\
\hline 0 & $121(62)$ & $26(68)$ & $147(63)$ \\
\hline 1 & $47(24)$ & $7(18)$ & $54(23)$ \\
\hline$\geq 2 \S$ & $27(14)$ & $5(13)$ & $32(14)$ \\
\hline \multicolumn{4}{|l|}{ Last known shunt locationł‡ } \\
\hline Ventriculoperitoneal & $152(84)$ & $23(61)$ & $175(80)$ \\
\hline Ventriculoatrial§ & $13(7)$ & $5(13)$ & $18(8)$ \\
\hline Complex peritoneal§ & $6(3)$ & $4(10)$ & $10(5)$ \\
\hline Cystoperitoneal & $2(1)$ & $1(3)$ & $3(1)$ \\
\hline Ventriculopleural† & $3(2)$ & $2(5)$ & $5(2)$ \\
\hline Subdural-peritoneal & $2(1)$ & $1(3)$ & $3(1)$ \\
\hline
\end{tabular}


» CONTINUED FROM PAGE 351

TABLE 3. Treatment decisions at the time of initial CSF shunt infection and intervening shunt revisions in children with and without CSF shunt reinfection

\begin{tabular}{|c|c|c|c|}
\hline Variable & No Reinfection & Reinfection & Entire Cohort \\
\hline \multicolumn{4}{|l|}{ Interval CSF shunt revision (continued) } \\
\hline \multicolumn{4}{|l|}{ Last known shunt locationł‡ } \\
\hline Complex atrial§ & $0(0)$ & $2(5)$ & $2(1)$ \\
\hline Lumboperitoneal & $1(1)$ & $0(0)$ & $1(0.5)$ \\
\hline Cystoatrial & $1(1)$ & $0(0)$ & $1(0.5)$ \\
\hline 4th ventricle-peritoneal & $1(1)$ & $0(0)$ & $1(0.5)$ \\
\hline Ultrasound use§,গT & $53(30)$ & $4(11)$ & 57 (26)ףा \\
\hline Endoscope use§,ף币 & $51(29)$ & $20(54)$ & 71 (33)ףा \\
\hline Antibiotic-impregnated catheter use $\| \rrbracket$ & $64(36)$ & $8(22)$ & 72 (33)ףा \\
\hline
\end{tabular}

Values are shown as the number of patients (\%) unless indicated otherwise.

* Reported for the 172 children diagnosed by CSF culture.

† Significant difference between groups $(p<0.10)$ according to the unadjusted Cox proportional hazards models.

‡ Reported for 120 patients. Medical complications included urinary tract infection, sepsis, pneumonia, cardiac arrest, pressure sores, deep venous thrombosis/pulmonary embolism, ascites, and hyponatremia. Neurological/surgical complications included CSF leak, wound infection, seizure, postoperative hemorrhage, pseudomeningocele, over- or underdrainage, intracranial fluid collection, and new neurological deficit.

$\S$ Significant difference between groups $(p<0.05)$ according to the unadjusted Cox proportional hazards models.

I Reported for 168 children diagnosed by CSF culture who underwent surgery.

** Reported for the 206 children who had 2 surgeries.

t† Reported for 153 of the 172 children diagnosed by CSF culture.

㧷 Reported for 219 children whose surgical approach to treatment changed the shunt location.

$\S \S$ Reported for 214 children for whom the approach to treatment involved surgery.

ๆๆ For postinfection revisions, 216 children had ultrasound, endoscope, and antibiotic-impregnated catheter use reported.

travenous antibiotic use was 15.8 days (SD 12.4 days). No differences were seen in reinfection for concordant and/or concordant and appropriate intravenous antibiotic use for $<$ 7 days, $<10$ days, or $<14$ days (data not shown). The median duration of broad-spectrum intravenous antibiotic use, which likely represents empirical antibiotic coverage while waiting for culture results and CSF clearance, was 5.3 days (IQR 2.8-13.6 days). The median duration of time from first negative culture to final surgical approach to treat infection, which best represents the number of days of therapy after CSF sterilization, was 13 days (IQR 9-20 days). A minority of initial CSF shunt infections were treated with additional rifampin (36 patients; 15\%). Medical complications were seen in $17 \%$ of the cohort and most commonly included hyponatremia ( 9 patients; $8 \%$ ) and urinary tract infection $(8$ patients; $7 \%$ ). Surgical complications were seen in $25 \%$ of the cohort and most commonly included minor CSF leak (8 patients; 7\%), wound infection (8 patients; 7\%), and seizure (8 patients; $7 \%$ ) (data not shown).

\section{Association With Reinfection}

In all Cox proportional hazards models, neither surgical approach for infection treatment nor overall intravenous antibiotic duration was independently associated with reinfection (Table 5). In the full model that included both the entire cohort and those patients with no revisions after infection, nonmodifiable factors, such as age, number of CCCs, and revisions after initial infection (for the complete cohort), were independently associated with reinfection. The only treatment decision independently associated with decreased infection risk was the use of rifampin.
In the time-varying hazards model, only revision after initial infection was independently associated with reinfection in the complete cohort, and the use of rifampin remained protective (Table 6). However, in the reduced model that used a stepwise approach without any variables forced into the model, 2 risk factors were consistently and independently associated with increased infection risk: 2 or more CCCs and nonventriculoperitoneal shunt location at last surgery. When children with nonventriculoperitoneal shunts were removed from the analysis, no factors were associated with reinfection. While these findings did not achieve statistical significance, both surgical approach other than total shut removal at initial CSF shunt infection and nonventriculoperitoneal shunt location were consistently associated with a higher hazard of reinfection, while the use of ultrasound was consistently associated with a lower hazard of reinfection in all 5 Cox proportional hazards models.

\section{Discussion}

This prospective cohort of 233 children treated for initial CSF shunt infection at 7 hospitals is the largest to date. The majority of patients were surgically treated with total shunt removal with EVD placement. The mean duration of concordant intravenous antibiotic use for those children diagnosed by CSF culture was 19 days. Neither surgical approach to treatment nor antibiotic duration was associated with reinfection risk. Nonmodifiable risk factors, such as age, number of CCCs, and revisions after initial infection, were independently associated with reinfection. The 
TABLE 4. Microbiological and diagnostic factors in children with and without CSF shunt reinfection at the time of initial CSF shunt infection

\begin{tabular}{|c|c|c|c|}
\hline Variable & No Reinfection & Reinfection & Entire Cohort \\
\hline No. of patients & 195 & 38 & 233 \\
\hline \multicolumn{4}{|l|}{ Diagnosis of infection* } \\
\hline CSF culture & $147(75)$ & $25(66)$ & $172(74)$ \\
\hline Wound infection excluding CSF culture & $19(10)$ & $3(8)$ & $22(9)$ \\
\hline Abdominal pseudocyst & $14(7)$ & $6(16)$ & $20(9)$ \\
\hline Exposed hardware & $13(7)$ & $2(5)$ & $15(6)$ \\
\hline Blood culture in ventriculoatrial shunt & $1(1)$ & $2(5)$ & $3(1)$ \\
\hline Gram stain only & $1(0)$ & $0(0)$ & $1(1)$ \\
\hline \multicolumn{4}{|l|}{ Organism identified $\dagger$} \\
\hline Coagulase-negative staphylococcus & $48(33)$ & $7(28)$ & $55(32)$ \\
\hline Staphylococcus aureus & $43(29)$ & $6(24)$ & $49(28)$ \\
\hline Other gram-positive organism & $18(12)$ & $7(28)$ & $25(15)$ \\
\hline Gram-negative organism & $34(23)$ & $4(16)$ & $38(22)$ \\
\hline$\geq 1$ organism & $4(3)$ & $0(0)$ & $4(2)$ \\
\hline Fungal & $0(0)$ & $1(4)$ & $1(1)$ \\
\hline Ventriculitis† & $19(13)$ & $4(16)$ & $23(13)$ \\
\hline Bacteremia & $15(8)$ & $4(11)$ & $19(8)$ \\
\hline Intermittent negative cultures $†$ & $23(16)$ & $2(8)$ & $25(15)$ \\
\hline No subsequent negative culture $†$ & $6(4)$ & $1(4)$ & $7(4)$ \\
\hline Median duration of positive CSF cultures $(I Q R)^{\star} \ddagger$ & $2.7(1.3-5.6)$ & $2.5(1.6-4.3)$ & $2.7(1.4-5.5)$ \\
\hline Initial positive Gram stain§ & $85(44)$ & $11(31)$ & $96(42)$ \\
\hline Median initial white blood cell count $\rrbracket$ & $47(5-333)$ & $42(4-233)$ & $47(5-307)$ \\
\hline Median initial red blood cell count (IQR)ף & $43(3-723)$ & $185(42-881)$ & $59(4-723)$ \\
\hline Median initial glucose $(\mathrm{IQR})^{\star *}$ & $45(28-60)$ & $41(25-61)$ & $44(27-60)$ \\
\hline Median initial protein $(\mathrm{IQR})^{\star *}$ & $87(25-280)$ & $102(23-499)$ & $90(25-298)$ \\
\hline
\end{tabular}

Values are shown as the number of patients (\%) unless indicated otherwise. No significant differences between groups were found according to the unadjusted Cox.

* Diagnosis of infection was assigned in a hierarchical fashion, with CSF culture being the most definitive and wound culture the least definitive.

† Evaluated in 172 children diagnosed by CSF culture.

$\ddagger$ Seven patients never had a negative culture obtained after the first positive culture.

$\S$ Evaluated for 231 infections.

II Evaluated for 224 infections.

** Evaluated for 219 infections.

only treatment decision that was consistently and independently associated with decreased reinfection risk was the use of rifampin. While these findings did not achieve statistical significance, surgical approach other than total shunt removal at initial CSF shunt infection and nonventriculoperitoneal shunt location were consistently associated with a higher hazard of reinfection, while the use of ultrasound was consistently associated with a lower hazard of reinfection in all 5 Cox proportional hazards models.

Key questions in the treatment of CSF shunt infection still include determination of the appropriate surgical therapy and appropriate duration of antibiotic therapy. ${ }^{43,54}$ While not statistically significant, a surgical approach other than total shunt removal at initial CSF shunt infection was consistently associated with a higher hazard of reinfection in this study. Additionally, the current study adds to the existing literature ${ }^{39,47}$ and, importantly, suggests the feasibility of controlling and standardizing the surgical approach (total shunt removal with EVD placement) to remove potential confounding effects in a trial aimed at identifying an optimal antibiotic regimen. Significant variation in antibiotic treatment decision making in the treatment of CSF shunt infection has been previously demonstrated. ${ }^{23,38,52}$ This study confirms that considerable variation, and therefore equipoise, exists in the duration and selection of intravenous antibiotic treatment. ${ }^{17}$ We believe future studies of the optimal duration of intravenous antibiotic treatment are critical to the creation of high-quality, evidence-based guidelines for CSF shunt infection treatment. A reasonable first step toward a randomized controlled trial would be to standardize treatment of CSF shunt infection and use standard surgical therapy for shunt removal and EVD placement and standard intravenous antibiotic therapy according to duration $^{38,46}$ and organism, as outlined in recent guidelines from the Infectious Diseases Societies of America. ${ }^{47}$

The only treatment decision that was consistently and independently associated with decreased reinfection risk in this cohort was the use of rifampin, which is thought to be effective against biofilms. Rifampin has been reported to be beneficial in case reports, ${ }^{4,13,29}$ case series, ${ }^{9}$ and re- 
TABLE 5. Factors independently associated with CSF shunt reinfection among children with infection

\begin{tabular}{|c|c|c|}
\hline \multirow[b]{2}{*}{ Variable } & \multicolumn{2}{|c|}{ Adjusted OR $(95 \% \mathrm{Cl})$} \\
\hline & Full Model for Full Cohort & $\begin{array}{l}\text { Children w/ No Revisions Btwn } \\
\text { Infection \& Reinfection }(n=147)\end{array}$ \\
\hline \multicolumn{3}{|l|}{ Chronological age at initial shunt placement } \\
\hline $0-1$ mos & $0.3(0.1-0.9)$ & $0.4(0.1-1.5)$ \\
\hline $1-6$ mos & $0.7(0.3-1.7)$ & $0.2(0.1-0.9)$ \\
\hline 6 mos-4 yrs & Referent & Referent \\
\hline$>4$ yrs & $0.1(0.0-0.6)$ & NR \\
\hline \multicolumn{3}{|l|}{ Etiology of hydrocephalus } \\
\hline Post-IVH due to prematurity & $0.6(0.3-1.5)$ & $1.2(0.3-4.5)$ \\
\hline Cyst (other intracranial, posterior fossa) & NR & \\
\hline \multicolumn{3}{|l|}{$\mathrm{CCCs}$} \\
\hline 0 (except hydrocephalus) & Referent & Referent \\
\hline 1 & $2.0(0.8-5.1)$ & $2.9(0.7-13.0)$ \\
\hline$\geq 2$ & $3.4(1.1-10.5)$ & $5.6(1.1-32.0)$ \\
\hline \multicolumn{3}{|l|}{ Revisions before initial CSF shunt infection } \\
\hline 0 & Referent & Referent \\
\hline 1 & $1.9(0.7-4.9)$ & $1.2(0.3-4.2)$ \\
\hline$\geq 2$ & $1.1(0.4-2.9)$ & $0.8(0.2-2.5)$ \\
\hline \multicolumn{3}{|l|}{ Visualization used before initial CSF shunt infection } \\
\hline Both & NR & NR \\
\hline Endoscope & $1.4(0.5-3.8)$ & $1.0(0.3-3.4)$ \\
\hline Ultrasound & $0.5(0.1-2.2)$ & $0.4(0.0-4.3)$ \\
\hline Neither & Referent & Referent \\
\hline Unknown & $0.4(0.1-1.4)$ & $0.3(0.0-1.9)$ \\
\hline Surgical approach to treatment of initial infection other than total removal & $1.7(0.6-4.2)$ & $3.2(0.8-11.7)$ \\
\hline No use of rifampin at initial CSF shunt infection & $4.2(1.1-27.6)$ & $7.9(1.1-173.1)$ \\
\hline \multicolumn{3}{|l|}{ Duration of overall IV antibiotic use } \\
\hline$<7$ days & $0.4(0.0-1.7)$ & $2.2(0.3-13.7)$ \\
\hline 8-14 days & Referent & Referent \\
\hline$>14$ days & $1.5(0.6-3.7)$ & $1.9(0.5-7.9)$ \\
\hline \multicolumn{3}{|l|}{ Visualization used at initial CSF shunt infection/last op prior to censor/reinfection } \\
\hline Endoscope & $0.9(0.3-2.2)$ & $2.8(0.8-10.9)$ \\
\hline Ultrasound & $0.3(0.0-1.5)$ & $0.4(0.0-2.1)$ \\
\hline Neither & Referent & Referent \\
\hline Nonventriculoperitoneal shunt location last known op prior to censor/reinfection & $1.6(0.6-3.9)$ & $1.9(0.6-6.3)$ \\
\hline \multicolumn{3}{|l|}{ Revisions after initial CSF shunt infection \& before censor/reinfection } \\
\hline 0 & Referent & \\
\hline 1 & $1.7(0.5-4.7)$ & \\
\hline$\geq 2$ & $7.0(1.8-25.0)$ & \\
\hline
\end{tabular}

IVH = intraventricular hemorrhage; NR = not reportable.

Boldface type indicates statistical significance.

view articles. ${ }^{7}$ Rifampin use was either not reported ${ }^{17,21}$ or not beneficial ${ }^{39}$ in more recent studies. Further consideration should be given to the use of rifampin in the treatment of CSF shunt infection, ${ }^{1}$ and rifampin use is recommended for susceptible organisms in recent guidelines from the Infectious Diseases Societies of America. ${ }^{47}$

Nonmodifiable risk factors, such as the number of CCCs and revisions after initial infection, were independently associated with reinfection in this cohort, which was not observed in earlier detailed studies of reinfection risk. ${ }^{17,21,39}$ While not statistically significant in this study, nonventriculoperitoneal shunt location was consistently associated with a higher hazard of reinfection, as observed in earlier work. ${ }^{39}$

We observed consistent approaches to visualization during neurosurgical procedures within centers, as well as within a given patient over time. While not statistically significant, the use of ultrasonography was consistently as- 


\begin{tabular}{|c|c|c|c|}
\hline \multirow[b]{2}{*}{ Factor } & \multicolumn{3}{|c|}{ Adjusted OR $(95 \% \mathrm{Cl})$} \\
\hline & $\begin{array}{l}\text { Time-Varying } \\
\text { Hazards Model }\end{array}$ & $\begin{array}{l}\text { Reduced } \\
\text { Model }\end{array}$ & $\begin{array}{l}\text { VP Shunt } \\
\text { Model }\end{array}$ \\
\hline \multicolumn{4}{|l|}{ Chronological age at initial shunt placement } \\
\hline $0-1$ mos & $0.4(0.1-1.3)$ & NR & $0.3(0.0-2.1)$ \\
\hline $1-6$ mos & $0.7(0.3-1.8)$ & NR & $0.3(0.1-1.0)$ \\
\hline 6 mos-4 yrs & Referent & NR & Referent \\
\hline$>4$ yrs & $0.2(0.0-1.2)$ & NR & ND \\
\hline \multicolumn{4}{|l|}{ Etiology of hydrocephalus } \\
\hline Post-IVH due to prematurity & $0.7(0.3-1.8)$ & NR & $1.6(0.4-7.0)$ \\
\hline Cyst (other intracranial, posterior fossa) & NR & NR & NR \\
\hline \multicolumn{4}{|l|}{ CCCs } \\
\hline 0 (except hydrocephalus) & Referent & Referent & Referent \\
\hline 1 & $1.7(0.6-4.7)$ & $1.9(0.8-4.5)$ & $3.6(0.8-17.3)$ \\
\hline$\geq 2$ & $3.1(1.0-9.9)$ & $5.6(2.0-14.9)$ & $3.8(0.6-26.5)$ \\
\hline \multicolumn{4}{|l|}{ Revisions before initial CSF shunt infection } \\
\hline 0 & Referent & NR & Referent \\
\hline 1 & $1.3(0.4-3.6)$ & NR & $1.4(0.3-6.0)$ \\
\hline$\geq 2$ & $0.9(0.3-2.4)$ & NR & $1.0(0.2-4.5)$ \\
\hline \multicolumn{4}{|l|}{ Visualization used before initial CSF shunt infection } \\
\hline Both & NR & NR & NR \\
\hline Endoscope & $2.0(0.7-5.8)$ & $2.2(1.0-5.1)$ & $1.1(0.2-6.7)$ \\
\hline Ultrasound & $0.7(0.1-3.4)$ & $0.4(0.1-1.6)$ & NR \\
\hline Neither & Referent & Referent & Referent \\
\hline Unknown & $0.5(0.1-2.3)$ & $0.4(0.1-1.6)$ & $0.8(0.1-6.0)$ \\
\hline Surgical approach to treatment of initial infection other than total removal & $2.0(0.6-5.5)$ & NR & $4.6(0.9-22.1)$ \\
\hline No use of rifampin at initial CSF shunt infection & $6.5(1.2-121.6)$ & NR & $4.8(0.7-96.3)$ \\
\hline \multicolumn{4}{|l|}{ Duration of overall IV antibiotic use } \\
\hline$<7$ days & $0.7(0.1-3.5)$ & NR & $2.1(0.2-15.2)$ \\
\hline $8-14$ days & Referent & NR & Referent \\
\hline$>14$ days & $1.8(0.7-5.1)$ & NR & $1.0(0.2-4.2)$ \\
\hline \multicolumn{4}{|l|}{ Visualization used at initial CSF shunt infection/last op prior to censor/reinfection } \\
\hline Endoscope & $0.9(0.3-2.7)$ & NR & $5.0(0.9-35.5)$ \\
\hline Ultrasound & $0.2(0.0-1.0)$ & NR & $0.2(0.0-2.6)$ \\
\hline Neither & Referent & NR & Referent \\
\hline Nonventriculoperitoneal shunt location last known op prior to censor/reinfection & $1.7(0.6-4.6)$ & $2.6(1.2-5.5)$ & NA \\
\hline \multicolumn{4}{|l|}{ Revisions after initial CSF shunt infection \& before censor/reinfection } \\
\hline 0 & Referent & NR & Referent \\
\hline 1 & $5.4(1.1-24.6)$ & NR & $9.2(0.6-104.0)$ \\
\hline$\geq 2$ & NR & NR & NR \\
\hline
\end{tabular}

NA = not applicable; ND = not determined.

Boldface type indicates statistical significance.

sociated with a lower hazard of reinfection in all 5 Cox proportional hazards models. This study adds to the literature by suggesting that the use of ultrasonography ${ }^{51}$ is associated with a lower risk of shunt failure ${ }^{6}$ or is of uncertain benefit. ${ }^{8,53}$ Although statistical significance was not observed in this cohort, the use of an endoscope before infection was associated with a higher hazard of reinfection in several models. This study adds to the literature by suggesting that the use of an endoscope either is not as- sociated with reduced shunt failure ${ }^{16}$ or is associated with a higher risk of shunt failure. ${ }^{32}$ These findings suggest that efforts to minimize instrumentation of the CSF may reduce infection risk.

This work has several limitations. The relatively low reinfection rate with a moderate sample size limits our power and ability to adjust for multiple variables, particularly those variables that are not significantly associated with reinfection or correlated with other predictors. Incor- 
porating variables with true predictive association with reinfection can reduce unexplained variance and illuminate associations with residual variance. However, we also challenged this by using both judicious model construction and reduced models. Conducting this study at HCRN centers that were adhering to an infection prevention bun$\mathrm{dle}^{18,19}$ reduces generalizability of the findings outside of HCRN. However, the HCRN prevention bundle has been widely disseminated and implemented in the past 5 years. In addition, the multiinstitutional nature of this study gives it greater generalizability than previous studies. The potential confounding of factors associated with treatment decision making and reinfection risk, such as the center, continues to be problematic. Surgeons may take into consideration individual patient and infection characteristics that are believed to be important enough to influence treatment and are likely to also be associated with treatment outcomes. For example, infection with a difficult-to-treat organism may result in a longer duration of antibiotic administration and may also be likely to reoccur. Our ability to disentangle these associations is limited in this study. Additional aspects of the management of CSF shunt infection-including but not limited to the number, frequency, and method of CSF culturing obtained through EVDs; flushing of EVDs; replacement of EVDs; and the use of antibiotic-impregnated EVDs-are not standardized in HCRN and were subject to variation within and between participating centers. Our definition of infection was developed by consensus within HCRN and does not permit easy comparison with infection rates at non-HCRN centers or those used by hospital infection control groups. For neurosurgical procedures, the assumption is that patients return to the same center for care, and therefore subsequent infections would be captured in our data. Drug levels were not available for the review and determination of concordant and appropriate intravenous antibiotic use.

\section{Conclusions}

Neither surgical approach to treatment nor antibiotic duration was associated with reinfection risk. While this finding did not achieve statistical significance, a surgical approach other than total shunt removal at initial CSF shunt infection was consistently associated with a higher hazard of reinfection in this study and suggests the feasibility of controlling and standardizing the surgical approach (shunt removal with EVD placement). Considerable variation, and therefore equipoise, exists in the duration and selection of intravenous antibiotic treatment. The only treatment decision that was consistently and independently associated with decreased reinfection risk in this cohort was the use of rifampin, and further consideration should be given to its use in the treatment of CSF shunt infection. High-quality studies of the optimal duration of antibiotic treatment are critical to the creation of evidence-based guidelines for CSF shunt infection treatment. A reasonable first step toward a randomized controlled trial would be to standardize the treatment of CSF shunt infection by standardizing both surgical shunt removal with EVD placement and intravenous antibiotic therapy and duration according to the recovered organism.

\section{Acknowledgments}

We thank the contributing children and families at all participating centers. We also thank Stephan John Nemeth IV, Gabriel Finn Nemeth, and Daschel Simon Nemeth (family of T.D.S.) for providing support and valuable feedback.

Funding was provided by the National Institute of Neurological Disorders and Stroke (award K23NS062900) and the National Center for Research Resources (CTSA grant no. ULI RR025014), a component of the National Institutes of Health (to T.D.S, K.B.W., N.E.G., and the Nemeth family); and National Institute of Neurological Disorders and Stroke grant no. 1RC1NS068943-01 (to the HRCN). None of the sponsors listed here or in Disclosures participated in the design and conduct of the study; the collection, management, analysis, and interpretation of the data; or the preparation, review, or approval of the article. Its contents are solely the responsibility of the authors and do not necessarily represent the official view of the funding sponsors.

\section{Appendix}

We thank our colleagues who kindly agreed to participate in this HCRN project and allowed collection of patient data for the purpose of this publication, as well as the outstanding support of the dedicated study coordinators at each clinical center and the data coordinating center:

Primary Children's Hospital, University of Utah, Salt Lake City, Utah: Douglas L. Brockmeyer, MD; Robert Bollo, MD, MS; and coordinators Jason Clawson, BA, Nicole Tattersall, RN, BSN, and Tracey Habrock-Bach, BS.

Children's of Alabama, University of Alabama at Birmingham, Alabama: Jeffrey P. Blount, MD; James M. Johnston, MD; Brandon Rocque, MD; and coordinators Anastasia Arynchyna, MPH, and Amita Bey, MPH.

The Hospital for Sick Children, University of Toronto, Ontario, Canada: James M. Drake, BSE, MBBCh, MSc (HCRN investigator); Leslie Ackacpo-Satchivi, MD, PhD; Peter B. Dirks, MD, PhD; James T. Rutka, MD, PhD; Michael D. Taylor, MD, PhD; and coordinators Homa Ashrafpour, BSc, and Lindsay O'Connor, MSc.

Texas Children's Hospital, Baylor College of Medicine, Houston, Texas: Daniel J. Curry, MD; Robert C. Dauser, MD; Andrew H. Jea, MD; Sandi K. Lam, MD; and coordinators Sheila Martinez, BS, and Sheila Ryan, JD, MPH.

Seattle Children's Hospital, University of Washington, Seattle, Washington: Richard G. Ellenbogen, MD; Jeffrey G. Ojemann, $\mathrm{MD}, \mathrm{PhD}$; Amy Lee, MD; Anthony Avellino, MD, PhD; and coordinators Amy Anderson, BSN, RN, and Gloria Bowen, MA.

Children's Hospital of Pittsburgh, University of Pittsburgh, Pennsylvania: Ian F. Pollack, MD; Stephanie Greene, MD; Elizabeth C. Tyler-Kabara, MD, PhD; and coordinators Kimberly Diamond, BS, BA, and Arlene Luther, BS, RN.

St. Louis Children's Hospital, Washington University in St. Louis, Missouri: T. S. Park, MD; Matthew D. Smyth, MD; Jeffrey R. Leonard, MD; and coordinator Deanna Mercer.

Monroe Carell Jr. Children's Hospital at Vanderbilt, Vanderbilt University Medical Center, Nashville, Tennessee: Robert P. Naftel, MD; Noel B. Tulipan, MD; and coordinator Stephen Gannon, BS, CCRP.

British Columbia Children's Hospital, University of British Columbia, Vancouver, British Columbia: Patrick McDonald, MD (HCRN investigator); Ash Singhal, MD, MSc; Paul Steinbok, MBBS; and coordinators Ross Hengel, BS, and Alexander Cheong, BS.

Alberta Children's Hospital, University of Calgary, Alberta, Canada: Walter Hader, MD; Clare Gallagher, MD; Mahmoud Benour, MD; and coordinator Salim Ahmed, MSc.

The Johns Hopkins Hospital, Johns Hopkins, Baltimore, Maryland: Edward Ahn, MD (HCRN investigator); Alan Cohen, MD; Mari Groves, MD; Eric Jackson, MD; and Shenandoah Robinson, MD. 
Children's Hospital of Los Angeles, University of Southern California, Los Angeles, California: Mark Krieger, MD (HCRN investigator); Erin Kiehna, MD; J. Gordon McComb, MD; Aaron Robison, MD; and coordinator Christina Artime, RN, BSN, MSHCM.

Children's Hospital Colorado, University of Colorado Denver Health Sciences Center, Aurora, Colorado: Todd Hankinson, MD (HCRN investigator); Michael Handler, MD; Brent O’Neill, MD; Corbett Wilkinson, MD; and coordinator Susan Staulcup.

Nationwide Children's Hospital, Ohio State University College of Medicine, Columbus, Ohio: Jonathan Pindrik, MD (HCRN investigator); Lance Governale, MD; Jeffrey Leonard, MD; Eric Sribnick, MD; and coordinator Adrienne Boczar, MPH.

HCRN Data Coordinating Center, Department of Pediatrics, University of Utah, Salt Lake City, Utah: Volker Freimann, BA; Nichol Nunn, BS, MBA; and Jeff Yearley, BA.

\section{References}

1. Achermann Y, Goldstein EJ, Coenye T, Shirtliff ME: Propionibacterium acnes: from commensal to opportunistic biofilm-associated implant pathogen. Clin Microbiol Rev 27:419-440, 2014

2. Albright AL, Pollack IF, Adelson PD, Solot JJ: Outcome data and analysis in pediatric neurosurgery. Neurosurgery 45:101-106, 1999

3. Andersen PK, Gill RD: Cox's regression model for counting processes: a large sample study. Ann Stat 10:1100-1120, 1982

4. Archer GL, Tenenbaum MJ, Haywood HB III: Rifampin therapy of Staphylococcus epidermidis. Use in infections from indwelling artificial devices. JAMA 240:751-753, 1978

5. Cochrane DD, Kestle J: Ventricular shunting for hydrocephalus in children: patients, procedures, surgeons and institutions in English Canada, 1989-2001. Eur J Pediatr Surg 12 (Suppl 1):S6-S11, 2002

6. Crowley RW, Dumont AS, Asthagiri AR, Torner JC, Medel $\mathrm{R}$, Jane JA Jr, et al: Intraoperative ultrasound guidance for the placement of permanent ventricular cerebrospinal fluid shunt catheters: a single-center historical cohort study. World Neurosurg 81:397-403, 2014

7. Fan-Havard P, Nahata MC: Treatment and prevention of infections of cerebrospinal fluid shunts. Clin Pharm 6:866880,1987

8. Flannery AM, Duhaime AC, Tamber MS, Kemp J: Pediatric hydrocephalus: systematic literature review and evidencebased guidelines. Part 3: Endoscopic computer-assisted electromagnetic navigation and ultrasonography as technical adjuvants for shunt placement. J Neurosurg Pediatr 14 (Suppl 1):24-29, 2014

9. Frame PT, McLaurin RL: Treatment of CSF shunt infections with intrashunt plus oral antibiotic therapy. J Neurosurg 60:354-360, 1984

10. Gardner P, Leipzig T, Phillips P: Infections of central nervous system shunts. Med Clin North Am 69:297-314, 1985

11. Gardner P, Leipzig TJ, Sadigh M: Infections of mechanical cerebrospinal fluid shunts. Curr Clin Top Infect Dis 9:185214, 1988

12. Griebel R, Khan M, Tan L: CSF shunt complications: an analysis of contributory factors. Childs Nerv Syst 1:77-80, 1985

13. Hellbusch LC, Penn RG: Treatment of haemophilus influenzae type B cerebrospinal fluid shunt infection with ceftriaxone and rifampin: case report. Nebr Med J 80:27-29, 1995

14. Kanev PM, Sheehan JM: Reflections on shunt infection. Pediatr Neurosurg 39:285-290, 2003

15. Kestle JRW: Pediatric hydrocephalus: current management. Neurol Clin 21:883-895, vii, 2003

16. Kestle JRW, Drake JM, Cochrane DD, Milner R, Walker ML, Abbott R III, et al: Lack of benefit of endoscopic ventriculo- peritoneal shunt insertion: a multicenter randomized trial. J Neurosurg 98:284-290, 2003

17. Kestle JRW, Garton HJ, Whitehead WE, Drake JM, Kulkarni AV, Cochrane DD, et al: Management of shunt infections: a multicenter pilot study. J Neurosurg 105 (3 Suppl):177-181, 2006

18. Kestle JRW, Holubkov R, Cochrane DD, Kulkarni AV, Limbrick DD Jr, Luerssen TG, et al: A new Hydrocephalus Clinical Research Network protocol to reduce cerebrospinal fluid shunt infection. J Neurosurg Pediatr 17:391-396, 2016

19. Kestle JRW, Riva-Cambrin J, Wellons JC III, Kulkarni AV, Whitehead WE, Walker ML, et al: A standardized protocol to reduce cerebrospinal fluid shunt infection: the Hydrocephalus Clinical Research Network Quality Improvement Initiative. J Neurosurg Pediatr 8:22-29, 2011

20. Kulkarni AV, Drake JM, Lamberti-Pasculli M: Cerebrospinal fluid shunt infection: a prospective study of risk factors. J Neurosurg 94:195-201, 2001

21. Kulkarni AV, Rabin D, Lamberti-Pasculli M, Drake JM: Repeat cerebrospinal fluid shunt infection in children. Pediatr Neurosurg 35:66-71, 2001

22. Kulkarni AV, Riva-Cambrin J, Butler J, Browd SR, Drake JM, Holubkov R, et al: Outcomes of CSF shunting in children: comparison of Hydrocephalus Clinical Research Network cohort with historical controls: clinical article. J Neurosurg Pediatr 12:334-338, 2013

23. Li V, Dias MS: The results of a practice survey on the management of patients with shunted hydrocephalus. Pediatr Neurosurg 30:288-295, 1999

24. McGirt MJ, Leveque JC, Wellons JC III, Villavicencio AT, Hopkins JS, Fuchs HE, et al: Cerebrospinal fluid shunt survival and etiology of failures: a seven-year institutional experience. Pediatr Neurosurg 36:248-255, 2002

25. McGirt MJ, Zaas A, Fuchs HE, George TM, Kaye K, Sexton DJ: Risk factors for pediatric ventriculoperitoneal shunt infection and predictors of infectious pathogens. Clin Infect Dis 36:858-862, 2003

26. Morissette I, Gourdeau M, Francoeur J: CSF shunt infections: a fifteen-year experience with emphasis on management and outcome. Can J Neurol Sci 20:118-122, 1993

27. Nelson JD: Cerebrospinal fluid shunt infections. Pediatr Infect Dis 3 (3 Suppl):S30-S32, 1984

28. Odio C, McCracken GH Jr, Nelson JD: CSF shunt infections in pediatrics. A seven-year experience. Am J Dis Child 138:1103-1108, 1984

29. O'Keeffe PT, Bayston R: Pneumococcal meningitis in a child with a ventriculo-peritoneal shunt. J Infect 22:77-79, 1991

30. Piatt JH Jr, Carlson CV: A search for determinants of cerebrospinal fluid shunt survival: retrospective analysis of a 14-year institutional experience. Pediatr Neurosurg 19:233242, 1993

31. Quigley MR, Reigel DH, Kortyna R: Cerebrospinal fluid shunt infections. Report of 41 cases and a critical review of the literature. Pediatr Neurosci 15:111-120, 1989

32. Riva-Cambrin J, Kestle JRW, Holubkov R, Butler J, Kulkarni $\mathrm{AV}$, Drake J, et al: Risk factors for shunt malfunction in pediatric hydrocephalus: a multicenter prospective cohort study. J Neurosurg Pediatr 17:382-390, 2016

33. Ronan A, Hogg GG, Klug GL: Cerebrospinal fluid shunt infections in children. Pediatr Infect Dis J 14:782-786, 1995

34. Schoenbaum SC, Gardner P, Shillito J: Infections of cerebrospinal fluid shunts: epidemiology, clinical manifestations, and therapy. J Infect Dis 131:543-552, 1975

35. Sells CJ, Shurtleff DB, Loeser JD: Gram-negative cerebrospinal fluid shunt-associated infections. Pediatrics 59:614-618, 1977

36. Shurtleff DB, Stuntz JT, Hayden PW: Experience with 1201 cerebrospinal fluid shunt procedures. Pediatr Neurosci 12:49-57, 1985-1986

37. Simon TD, Hall M, Dean JM, Kestle JRW, Riva-Cambrin J: 
Reinfection following initial cerebrospinal fluid shunt infection. J Neurosurg Pediatr 6:277-285, 2010

38. Simon TD, Kronman MP, Whitlock KB, Gove N, Browd SR, Holubkov R, et al: Variability in management of first cerebrospinal fluid shunt infection: a prospective multi-institutional observational cohort study. J Pediatr 179:185-191.e2, 2016

39. Simon TD, Mayer-Hamblett N, Whitlock KB, Langley M, Kestle JRW, Riva-Cambrin J, et al: Few patient, treatment, and diagnostic or microbiological factors, except complications and intermittent negative cerebrospinal fluid (CSF) cultures during first CSF shunt infection, are associated with reinfection. J Pediatric Infect Dis Soc 3:15-22, 2014

40. Simon TD, Riva-Cambrin J, Srivastava R, Bratton SL, Dean JM, Kestle JRW: Hospital care for children with hydrocephalus in the United States: utilization, charges, comorbidities, and deaths. J Neurosurg Pediatr 1:131-137, 2008

41. Simon TD, Whitlock KB, Riva-Cambrin J, Kestle JRW, Rosenfeld M, Dean JM, et al: Association of intraventricular hemorrhage secondary to prematurity with cerebrospinal fluid shunt surgery in the first year following initial shunt placement. J Neurosurg Pediatr 9:54-63, 2012

42. Simon TD, Whitlock KB, Riva-Cambrin J, Kestle JRW, Rosenfeld M, Dean JM, et al: Revision surgeries are associated with significant increased risk of subsequent cerebrospinal fluid shunt infection. Pediatr Infect Dis J 31:551-556, 2012

43. Tamber MS, Klimo P Jr, Mazzola CA, Flannery AM: Pediatric hydrocephalus: systematic literature review and evidencebased guidelines. Part 8: Management of cerebrospinal fluid shunt infection. J Neurosurg Pediatr 14 (Suppl 1):60-71, 2014

44. Therneau TM, Hamilton SA: rhDNase as an example of recurrent event analysis. Stat Med 16:2029-2047, 1997

45. Tuan TJ, Thorell EA, Hamblett NM, Kestle JRW, Rosenfeld M, Simon TD: Treatment and microbiology of repeated cerebrospinal fluid shunt infections in children. Pediatr Infect Dis J 30:731-735, 2011

46. Tunkel AR, Hartman BJ, Kaplan SL, Kaufman BA, Roos KL, Scheld WM, et al: Practice guidelines for the management of bacterial meningitis. Clin Infect Dis 39:1267-1284, 2004

47. Tunkel AR, Hasbun R, Bhimraj A, Byers K, Kaplan SL, Michael Scheld W, et al: 2017 Infectious Diseases Society of America's clinical practice guidelines for healthcare-associated ventriculitis and meningitis. Clin Infect Dis 64:e34e65, 2017

48. Venes JL: Infections of CSF shunt and intracranial pressure monitoring devices. Infect Dis Clin North Am 3:289-299, 1989

49. Vinchon M, Dhellemmes P: Cerebrospinal fluid shunt infection: risk factors and long-term follow-up. Childs Nerv Syst 22:692-697, 2006

50. Walters BC, Hoffman HJ, Hendrick EB, Humphreys RP: Cerebrospinal fluid shunt infection. Influences on initial management and subsequent outcome. J Neurosurg 60:10141021,1984

51. Whitehead WE, Jea A, Vachhrajani S, Kulkarni AV, Drake JM: Accurate placement of cerebrospinal fluid shunt ven- tricular catheters with real-time ultrasound guidance in older children without patent fontanelles. J Neurosurg 107 (5 Suppl):406-410, 2007

52. Whitehead WE, Kestle JRW: The treatment of cerebrospinal fluid shunt infections. Results from a practice survey of the American Society of Pediatric Neurosurgeons. Pediatr Neurosurg 35:205-210, 2001

53. Whitehead WE, Riva-Cambrin J, Wellons JC III, Kulkarni AV, Holubkov R, Illner A, et al: No significant improvement in the rate of accurate ventricular catheter location using ultrasound-guided CSF shunt insertion: a prospective, controlled study by the Hydrocephalus Clinical Research Network. J Neurosurg Pediatr 12:565-574, 2013

54. Williams MA, McAllister JP, Walker ML, Kranz DA, Bergsneider M, Del Bigio MR, et al: Priorities for hydrocephalus research: report from a National Institutes of Health-sponsored workshop. J Neurosurg 107 (5 Suppl):345-357, 2007

55. Younger JJ, Christensen GD, Bartley DL, Simmons JC, Barrett FF: Coagulase-negative staphylococci isolated from cerebrospinal fluid shunts: importance of slime production, species identification, and shunt removal to clinical outcome. J Infect Dis 156:548-554, 1987

56. Younger JJ, Simmons JC, Barrett FF: Operative related infection rates for ventriculoperitoneal shunt procedures in a children's hospital. Infect Control 8:67-70, 1987

\section{Disclosures}

Dr. Limbrick: non-study-related clinical or research support from Medtronic, Karl Storz, Inc., Microbot Medical, Inc., National Institute of Neurological Disorders and Stroke, Patient-Centered Outcomes Research Institute, Hydrocephalus Association, and Rudy Schulte Research Institute. Dr. Simon, the Nemeth family, Ms. Whitlock, and Dr. Gove: support from Seattle Children's Center for Clinical and Translational Research. HCRN: funding from private philanthropy, The Gerber Foundation (1692-3638), Patient-Centered Outcomes Research Institute (CER-1403-13857), and the Hydrocephalus Association.

\section{Author Contributions}

Conception and design: Simon, Whitlock, Mayer-Hamblett, Oakes. Acquisition of data: Simon. Analysis and interpretation of data: Simon, Kronman, Whitlock, Gove. Drafting the article: Simon. Critically revising the article: Kronman, Whitlock, Gove, Mayer-Hamblett, Holubkov, Kulkarni, Langley, Riva-Cambrin, Rozzelle, Whitehead, Kestle. Reviewed submitted version of manuscript: all authors. Approved the final version of the manuscript on behalf of all authors: Simon. Statistical analysis: Whitlock, Gove. Study supervision: Simon.

\section{Correspondence}

Tamara D. Simon: University of Washington/Seattle Children's Hospital, Seattle, WA. tamara.simon@seattlechildrens.org. 